Journal of Applied Pharmaceutical Science Vol. 7 (03), pp. 212-216, March, 2017

Available online at http://www.japsonline.com

DOI: $10.7324 / \mathrm{JAPS} .2017 .70334$

ISSN 2231-3354 (cc)) EY-NC-SA

\title{
Relation between diabetes mellitus, thyroid hormones and caffeine
}

\author{
Luiz Augusto da Silva ${ }^{1,3^{*}}$, Jéssica Wouk ${ }^{2}$, Vinícius Müller Reis Weber ${ }^{3}$, Carlos Ricardo Maneck Malfatti ${ }^{3}$, Raul Osiecki \\ ${ }^{1}$ Post-graduation of Physical Education, Federal university of Paraná, Curitiba, Paraná, Brazil; Physical Education Department, Midw est State University \\ of Paraná, Guarapuava, Paraná, Brazil. Post-graduation of Pharmaceutical Science, Midwest State University of Paraná, Guarapuava, Paraná, Brazil. \\ ${ }^{3}$ Physical Education Department, Midwest State University of Paraná, Guarapuava, Paraná, Brazil.
}

\section{ARTICLE INFO \\ Article history: \\ Received on: 03/10/2016 \\ Accepted on: $17 / 11 / 2016$ \\ Available online: 30/03/2017}

Key words:

Insulin resistance, insulin, glucose, metabolism.

\begin{abstract}
Diabetes mellitus (DM) has an important relation with thyroid hormones (TH) dysfunctions, and if analyzed accurately, may contribute to the diagnosis of clinical conditions such as hyperglycemia and insulin resistance (IR). Relevant studies are being made about the role of TH in mediating metabolic actions related to DM, acting in many glands and energetic subtracts regulator tissues. Some issues, such as the action of TH over the ionic regulation in the cells, altering actions in different paths; its role over the negative feedback by downregulations upon insulin action, but provoking an increase in $\beta$ pancreatic cells proliferations, point out important directions to research. The mechanisms of action related to thyroid hormones and the insulinotropic action form a counterbalance, and if an imbalance occur (hyperthyroidism or hypothyroidism) it may be noted the presence of DM or IR. The interactions between TH, DM and caffeine are unknown aspects in the literature, which need a better attention and the development of experimental clinic studies to elucidate their mechanisms and clinical applications.
\end{abstract}

\section{INTRODUCTION}

Thyroid hormones $(\mathrm{TH})$ regulate essential metabolic process to a normal growth and development, they also regulate the organism metabolism, correlating the body weight and the expenditure of energy (Knudsen et al., 2005; Fox et al., 2008; Iwen et al., 2013; Gnocchi et al., 2016). The complex system of negative feedback involving the thyroid glands, synthesizes and secretes in blood circulation the hormones thyroxine $\left(\mathrm{T}_{4}\right)$ and triiodothyronine $\left(\mathrm{T}_{3}\right)$ related to pituitary gland, that produces the thyroid-stimulation hormone (TSH or thyrotropin). This hormone stimulates the synthesis of $\mathrm{TH}$ in the thyroid gland, being the secretion of TSH inhibited by the increase of TH. Hormonal concentrations of $T_{3}$ and $T_{4}$ are determined by thyrotropinreleasing hormone (TRH), produced in the hypothalamus in the

Corresponding Author

Luiz Augusto Da Silva, Post-graduation of Physical Education, Federal university of Paraná, Curitiba, Paraná, Brazil; Physical Education

Department, Midwest State University of Paraná, Guarapuava, Paraná, Brazil.Email:lasilva7 @ hotmail.com paraventricular nucleus, which stimulates the liberations of TSH of pituitary gland. TRH is inhibited by TH (Filiers, 2009; Ortiga-Carvalho et al., 2016). Hyperthyroidism, excess of TH, triggers a hypermetabolic state characterized by the increase of released energy at rest, weight loss, reduction in cholesterol levels and increase of lipolysis and gluconeogenesis (Motomura et al., 1998; Brent, 2008; Da Poian and Castanho, 2015). Conversely, hypothyroidism characterizes the reduction of energy liberation, weight gain, increase of cholesterol levels, reduction of lipolysis and gluconeogenesis (Brent, 2012). A chain of adrenergic innervations in thyroid gland stimulates the control of activation and liberation of TH, influencing the response of TSH stimulation (Sundler et al., 1989). Catecholamine (cortisol, adrenaline) increase the conversion of $\mathrm{T}_{4}$ to $\mathrm{T}_{3}$ through the specific activity of deubiquitinase enzyme that acts over the activity of up regulators of deubiquitin 2 protein, enhancing the levels of $\mathrm{T}_{3}$ in the thyroid cellular nucleus (Gereben et al., 2008). This synergism between TS and sympathetic nervous system (SNS) may be involved in alteration of energy storage or liberation (Ribeiro et al., 2001). 
The influence of TH over the metabolic pathway that controls energy emerge through the balance of energy storage and liberation (Cheng et al., 2010; Liu et a., 2010; Iwen et al., 2013) maintaining the endocrine regulators with actions over the brain, white and brown adipose tissue, skeletal muscle, liver and pancreas. The focus of $\mathrm{TH}$ over the energetic action, and over the regulation of lipids and carbohydrates metabolic pathways, describes the influence of these hormones over pathological conditions such as diabetes mellitus (DM).

$\mathrm{TH}$ triggers the raise of fatty acids in plasma in hyperthyroidism conditions. The reduction of intracellular levels of fatty acids are associated with the hepatic sensibility through modulation of substrate capitation by insulin and lipid oxidation (Chavez e Summers, 2010).

\section{Thyroid hormones over insulin and glucose metabolism}

TH are crucial to glucose homeostasis (Wennlund et al., 1986; Kim et al., 2002), and in contrast, insulin is the first hormone responsible for the glucose control, that leads us to suppose that there may be a relation in the effect of $\mathrm{T}_{3}$ and insulin, determining lipid and glucose metabolic pathways (Lambardiari et $a l, 2011)$. Recent studies indicate that euthyroid individuals may have fluctuations in the concentrations of $\mathrm{TH}$ in plasma, correlating to changes in the insulin secretion and sensibility (Ortega et al., 2008; Roos et al., 2007). Lambardiari et al, (2011) evaluated euthyroid subjects in early stage of DM type 2 (DMT2), investigating the association of $\mathrm{TH}$ levels with the sensibility of glucose by the insulin metabolism, and it was detected that the levels of $T_{3}$ and $T_{4}$ were reduced in the individuals with DMT2 compared with the control group.

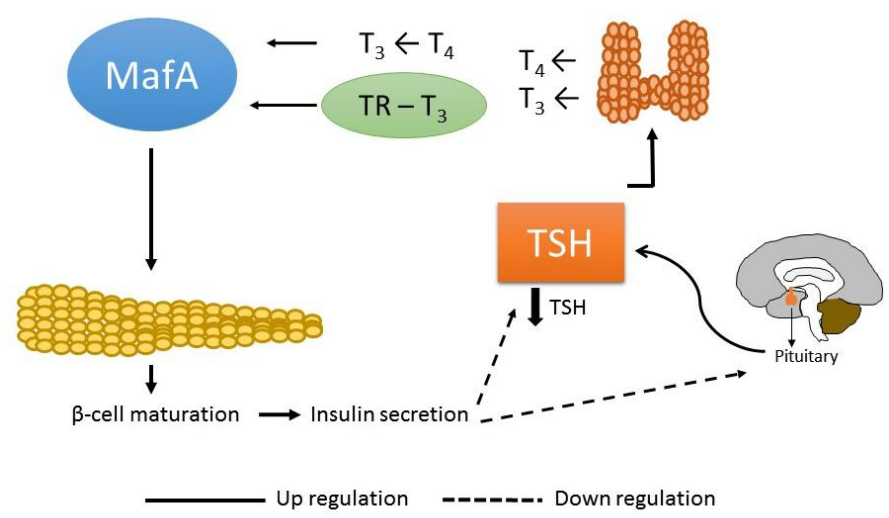

Fig. 1: Role of insulin in control of thyroid hormones through hypothalamicpituitary axis.

In pancreas, receptors of $\mathrm{TH}$ are important for a normal development of the islets. $M A F$ gene encode transcription factors, and the expression of MafA isotype has as its main objective to regulate the growth, proliferation and development of $\beta$ pancreatic cells (Aramata et al., 2007). It is suggested that TH may physiologically regulate the expressions of MafA, increasing its expressions and directing insulin secretion maturation, regulated by glucose, in $\beta$ pancreatic cells of neonate mice; whereas the inhibition of thyroid hormones' synthesis prevents or delays the maturation of these systems, and $\mathrm{TH}$ administration results in a precocious development of the tissue (Aguayo-Mazzucato et al., 2013) (Figure 1). In vitro, $\mathrm{T}_{3}$ has not altered the insulin secretion stimulated by glucose and may play an important role in the maturation of $\beta$ cells of neonate mice (Aguayo-Mazzucato et al., 2013), demonstrating to be relevant to insulin homeostasis.

TH inhibit the insulin liberation stimulated by glucose, associated with SNS actions, triggering an increase in glucose utilization and oxidation in islets, describing then, an action of downregulation (Mullur et al., 2014). This stimulus occurs due to the adrenergic action over thyroid gland, enhancing the liberation and conversion of $\mathrm{TH}$ and causing a consequent rise in glucose levels.

In contrast, the treatment with $\mathrm{T}_{3}$ prevents the damage and maintainx the structure, size and consistence of $\beta$ cells of streptozotocin-induced diabetic animal models (Verga et al., 2011), propitiating an increase of insulin liberation (Figure 1). The treatment with $\mathrm{T}_{3}$ prevented hyperinsulinemia, but not the hyperglycemia, in obese animals (Torrance et al., 1997). Therefore, $\mathrm{TH}$ act in the maturation and development of $\beta$ cells, albeit controlling the insulin clearance due to a synergic stimulation with SNS, maintaining the glucose homeostasis (Moog et al., 2015).

Is has been stablished that in hyperthyroidism condition a stimulation of gluconeogenesis occurs, as well as a reduction of it in hypothyroidism (Comte et al., 1990). The treatment with $\mathrm{T}_{4}$ increases alanine transportation to the hepatocytes, enhancing gluconeogenesis by alanine conversion to glucose (Singh et al., 1978). Moreover, the treatment with $T_{3}$ demonstrated to increase genes that regulate glycogenolysis and gluconeogenesis in liver (Feng et al., 2000; Gnocchi et al., 2016).

\section{Relation between diabetes and thyroid hormones}

Insulin resistance (IR) and the function of $\beta$ cells are inversely correlated to $\mathrm{TH}$ stimulation, explained by the antagonist effects of TH over insulin along the TSH enhancement. The increase of serum TSH usually demonstrates a reduction in $\mathrm{TH}$ levels by negative feedback mechanism, as well as the increase in $\mathrm{TH}$ levels decreases the effects of insulin in tissues (Chen et al., 2010; Nishanth et al., 2016).

$\mathrm{TH}$ act directly in the insulin secretion (Figure 1). In the hypothyroidism condition there is an increase of insulin secretion stimulated by glucose in the $\beta$ cells, and the opposite occurs in the hyperthyroidism condition, reducing the secretion of insulin stimulated by glucose (Stanick et al., 2005; Mitrou et al., 2010). Furthermore, an increase in insulin clearance occurs also during thyrotoxicosis disorder (Stanick et al., 2005). The deregulation of TH may affect the glucose homeostasis, acting over the reduction of the mitochondrial activity, what shows a link between the described action of TH and DM (Crunkhorn e Patti, 2008), however this relation is still unknown. 
The influence of IF over the hypothalamic-pituitary axis has been discussed in the literature, yet, conflicting results are reported, showing a positive association between homeostatic model assessment (HOMA) and TSH, while negative relations between IR and $\mathrm{T}_{4}$ were found by the same authors, or denied by others (Ambrosi et al., 2010). In DM condition, different investigations show that the serum levels influence in the control of diabetic condition and suggest a relation between the decrease of $\mathrm{T}_{3}$ production and the worsening of glucose utilization (Schlienger et al., 1982). Furthermore, thyrotoxicosis causes hyperinsulinemia with $\mathrm{TH}$ reduction and an increased glucose synthesis, what, by unknown mechanisms, triggers IR (AguayoMazzucato et al., 2013). Thus, the association between the production and the metabolism of carbohydrates was evaluated in diabetic patients, and a reduction in $\mathrm{T}_{3}$ production was shown, being correlated with a reduction in glucose utilization.

Hypothyroidism reduces the production of liver glucose and may trigger IR by unknown factors (Aguayo-Mazzucato et al., 2013). Ambrosi et al (2010) showed an increase in TSH levels in obese patient with IR $(1.8 \pm 1.0$ vs $1.6 \pm 0.9 \mu \mathrm{UI} / 1 ; p=0.03)$ and reduction of serum $\mathrm{T}_{4}(13.8 \pm 2.3$ vs $15.0 \pm 2.2 \mathrm{pmol} / \mathrm{l} ; p<0.001)$, when compared to patients with normal insulin sensibility. Moreover, a positive relation occurred between fasting insulin values $(p<0.001, \mathrm{r}=0.152)$ and HOMA (HOMA-IR; $p<0.001$, $\mathrm{r}=0.148$ ). The relation between thyroid function, obesity and DMT2 seems to exist, mainly influenced by IR. In Lambardiari et al, (2011) study, HOMA-IR was positively associated with $\mathrm{T}_{3}$ and $\mathrm{T}_{4}$, suggesting that the levels of $\mathrm{TH}$ are positively associated with IR, what may be part of the pathological mechanism to explain the beginning of DMT2 progress.

Hyperthyroidism is being associated with metabolic syndrome and cardiovascular disease components (Ichiki 2010). In euthyroidism, there is a positive relation between $\mathrm{T}_{4}$ and TSH concentrations and cardio metabolic variables. $\mathrm{T}_{3}$ hormone is reduced in some situations such as obesity, insulin concentrations, IR, diastolic and systolic pressure and dyslipidemias; however it is favored by hyperglycemia (De Pergola 2010). The risk of IF increases if the individual has reduced concentration of free $T_{4}$ (Luna-Vasquez et al., 2014). Moreover, evidences indicate that there is a reduction of $\mathrm{T}_{3}$ in diabetic subjects (Saunders, 1978).

\section{Ions regulation by thyroid hormones}

It is known that $\mathrm{T}_{3}$ hormone is important for a normal development of skeletal muscle, and a healthy thyroid gland is required to the development of the muscular mass and also to the differentiation of biochemical and contractile characteristics of the muscle (Finkelstein et al., 1991). This hormone has a great impact over the composition of the isoforms properties of myosin and sarcoplasmic reticulum (SR). Hypothyroidism causes some changes in the SR, enducing an enhancement in the transport of $\mathrm{Ca}^{++}$of SR and in the percentage of expressed protein fibers to SR $\mathrm{Ca}^{++}$ATPase enzymes in the skeletal muscles of rats (Li et al., 1996). Thyroid hormone responsive elements were found in genes that codify proteins of myocardial contraction and $\mathrm{Ca}^{++}$ homeostasis regulators (Forini et al., 2001). Evidences suggest a reduction of $45 \%$ in the $\mathrm{Ca}^{++}$myosine ATPase activity in diabetic animals (Malhotra et al., 1979), similar to the reductions that occurs during hypothyroidism (Dillmann, 1980). In hypertireoidic and diabetic animals a significant reduction of $\mathrm{Ca}^{++}$myosine ATPase activity occurred, however, the administration of $0.3 \mu \mathrm{g}$ of $\mathrm{T}_{3} / 100 \mathrm{~g}$ BW/day normalized the enzyme activity in hypertireoidic animals, but failed again in diabetic animals (Dillmann, 1982).

Hyperthyroidism is related to the enhancement of protein kinase C (PKC), this type of protein is responsible to control the phosphorylation of insulin receptor and consequently the IR, what may be reversible with TH treatment. PKC enzymes are activated by signals; such as rises in the diacylglycerol (DAG) or in calcium ions $\left(\mathrm{Ca}^{++}\right)$concentrations. These enzymes play an important role in several signal transduction cascades (Lin et al, 2008). The chronic exposition to $\mathrm{T}_{3}$ triggers a late internal increase of $\mathrm{Ca}^{++}$and an external enhancement of $\mathrm{K}$. Thus, a long exposition of $\mathrm{T}_{3}$ enhances the time of $\mathrm{Na}^{+}$channels inactivation in cardiac myocytes, increasing the $\mathrm{Na}^{+}$channels flow in ventricular myocytes and also increasing cellular $\mathrm{Ca}^{++}$harvesting in the myocytes (Wang et al., 2002).

\section{Caffeine and thyroid hormones}

Caffeine is an inhibitor of phosphodiesterase, and may influence hormonal secretion or inhibition by the rise of cyclic adenosine monophosphate (cAMP), or indirectly, affecting neurotransmitters and consequently hypothalamic clearance factors (Arnaud, 2011). Caffeine is rapidly absorbed by the gastrointestinal system and reveals plasma concentration peaks between 30 and 60 minutes. Only 1 to $3 \%$ of caffeine is excreted without any modification in urine. The metabolic rate of caffeine is variable, with a half-life of 4 to 6 hours (Panchal et al., 2012).

It is known that high doses of caffeine $(200 \mathrm{mg} / \mathrm{kg})$ may affect the secretion of several hormones, and in short-term experiments (1week) a reduction in TSH secretion was shown after a daily caffeine intake (Spindel et al., 1983; Spindel and Wurtman, 1984). Bartsch et al., (1996) aimed to elucidate the effect of a sub-chronical consumption of caffeine over thyroid (per 90 days $-104 \mathrm{mg} / \mathrm{kg} /$ day). This study demonstrated an increase of body weight to the animals that consumed caffeine, however, no alterations occurred in $\mathrm{T}_{3}$ and $\mathrm{T}_{4}$ levels, adrenal weight, histopathology of thyroid on the $21^{\text {st }}$ and $90^{\text {th }}$ day. Spindel et al., (1980) showed that caffeine may reduce $\mathrm{TSH}$ and $\mathrm{GH}$ concentration in a dosage of $50 \mathrm{mg} / \mathrm{Kg}$. The reduction of $\mathrm{TSH}$ was followed by a $\mathrm{T}_{3}$ and $\mathrm{T}_{4}$ reduction after $4 \mathrm{~h}$ of caffeine administration. In vitro, caffeine did not alter significantly the hormonal secretion of pituitary cells.

The glucose harvesting by $\beta$ pancreatic cells is performed by an insulin-independent glucose transporter, glucose transporter 2 (GLUT2). GLUT2 transports glucose to cytosol, after the conversion of this molecule and formation of adenosine triphosphate (ATP) occur. The enhancement of ATP block ATPsensitive potassium channels (KATP channels), increasing intracellular $\mathrm{K}^{+}$, triggering a depolarization of the membrane and 
an input of $\mathrm{Ca}^{++}$, trough voltage-dependent calcium channels (VDCC). The elevation of $\left[\mathrm{Ca}^{++}\right]_{\mathrm{i}}$ concentration stimulates the secretion of insulin, presumably by the liberation of the molecule storage in the $\beta$ cells granules (Quesada et al., 2006). It has been reported that caffeine may stimulate insulin secretion trough $\beta$ pancreatic cells, due to the rise of intracellular $\mathrm{Ca}^{++}$(Park et al., 2009).

In the skeletal muscle, insulin bind to its receptor causing the phosphorylation of the tyrosine of the receptor, resulting in insulin receptor substrates (IRS-1 and 2), IRS1 and 2 mediate the effects of insulin over glucose metabolism, through the activation of phosphatidylinositol (PI)-3 kinase and PKA/AKt and by the increase of GLUT4 and glycogen synthase (GS) (Defronzo, 2010). However, once the insulin receptor is not operating with its hormone, an insulin resistance occurs and the metabolism of glucose does not occur (D'Agostino et al., 2001). Caffeine may increase the expression of GLUT, due to an enhancement of $\mathrm{Ca}^{++}$ intracellular and also to the expression of the enzyme activated by AMD (AMPK) (Park et al., 2009; Conde et al., 2012).

Therefore, possibly with the insulinotropic action of caffeine, there is a reduction of $\mathrm{TH}$ concentration, triggering a balance in the influx of cellular substrates and perhaps, a greater catalytic action of the energetic substrates, in tissues such as the skeletal muscle and adipose tissue, as well as, a production and liberation of energy by the cell, due to the increased concentration of intracellular $\mathrm{Ca}^{++}$caused by caffeine.

\section{Conclusion and future perspectives}

An important progress occurred in the comprehension of $\mathrm{TH}$ roles mediating metabolic actions related to DM, acting in several glands and energetic substrates regulator tissues. Some theme, such as the action of TH over the ionic regulation in the cells altering their activity in different paths; as well as, over a negative feedback by downregulation on insulin action, increasing pancreatic $\beta$ cells, indicate important directions to research. The action mechanisms related to thyroid hormones and insulinotropic action form a counterbalance, in which occurring an imbalance (hyper or hypothyroidism) it may be observed the presence of DM or IR. The interaction between TH, DM and caffeine is still an unknown issue in the literature, that needs better attention and the development of new experimental clinical studies in order to elucidate its mechanisms and clinical application.

\section{ACKNOWLEDGMENT}

This work was supported by the Brazilian agencies: CNPq, National Council for Science and Technology and FA, Araucária Foundation from Paraná State. There is no potential conflict of interest.

\section{REFERENCES}

Aguayo-Mazzucato C., Zavacki AM., Marinelarena A., Hollister-Lock J., El Khattabi I., Marsili A., Weir GC., Sharma A., Larsen PR., Bonner-Weir S. Thyroid Hormone Promotes Postnatal Rat Pancreatic
b-Cell Development and Glucose-Responsive Insulin Secretion Through MAFA. Diabetes, 2013;62(5):1569-80.

Ambrosi B., Masserini B., Iorio L., Delnevo A., Malavazos AE., Morricone L., Sburlati LF., Orsi E. Relationship of thyroid function with body mass index and insulin-resistance in euthyroid obese subjects. J Endocrinol Invest, 2010;33(9):640-3.

Aramata S., Han SI., Kataoka K. Roles and regulation of transcription factor MafA in islet beta-cells. Endocr J, 2007;54(5):659-66.

Arnaud MJ. Pharmacokinetics and metabolism of natural methylxanthines in animal and man. Handb Exp Pharmacol, 2011;200:3391.

Bartsch W., Dasenbrock C., Ernst H., Kamino K., Mohr U. Absence of Effect of Caffeine on the Thyroid in the Syrian Golden Hamster Results of a 90-Day Study. Food Chem Toxicol, 1996;34(2):1539.

Brent GA. Clinical practice. Graves' disease. N Engl J Med, 358: 2594-2605, 2008.

Brent GA. Hypothyroidism and thyroiditis. In: Williams Textbook of Endocrinology, edited by Melmed SP, Larsen PR, and Kronenberg HM. Philadelphia, PA: Elsevier, 2012.

Chavez JA., Summers SA. Lipid oversupply, selective insulin resistance, and lipotoxicity: molecular mechanisms. Biochimica et Biophysica Acta, 1801(3):252-265, 2010.

Chen G., Wu J., Lin Y. Associations between cardiovascular risk, insulin resistance, $\beta$-cell function and thyroid dysfunction: a crosssectional study in She ethnic minority group of Fujian Province in China. Eur J Endocrinol, 2010;163(5):775-782.

Cheng SY., Leonard JL., Davis PJ. Molecular aspects of thyroid hormone actions. Endocr Rev, 2010;31: 139-170,

Comte B, Vidal H, Laville M, Riou JP. Influence of thyroid hormones on gluconeogenesis from glycerol in rat hepatocytes: a doseresponse study. Metabolism, 1990;39:259-263,

Conde SV., Silva TN., Gonzalez C., Carmo MM., Monteiro EC., Guarino MP. Chronic caffeine intake decreases circulating catecholamines and prevents diet-induced insulin resistance and hypertension in rats. $\mathrm{Br} \mathrm{J}$ Nutr, 2012;107(1):86-95. doi: 10.1017/S0007114511002406.

Crunkhorn S., Patti ME. Links between thyroid hormone action, oxidative metabolism, and diabetes risk? Thyroid 18: 227-237, 2008.

D'Agostino RB., Grundy S., Sullivan LM. Validation of the Framingham coronary heart disease prediction scores: results of a multiple ethnic groups investigation. JAMA, 2001;286:180-187.

Da Poian AT., Castanho MARB. Control of Body Weight and the Modern Metabolic Diseases. Integrative Human Biochemistry. 2015; 375-407.

De Pergola G., Ciampolillo A., Alò D. Free triiodothyronine is associated with smoking habit, independently of obesity, body fat distribution, insulin, and metabolic parameters. J Endocrinol Invest, 2010;33(11):815-818.

Defronzo RA. Current issues in the treatment of type 2 diabetes. Overview of newer agents: where treatment is going. Am J Med, 2010;123, 38-48. doi: 10.1016/j.amjmed.2009.12.008.

Dillmann WH: Diabetes mellitus induces changes in cardiac myosin of the rat. Diabetes, 1980;29:579-582.

Feng X., Jiang Y., Meltzer P., Yen PM. Thyroid hormone regulation of hepatic genes in vivo detected by complementary DNA microarray. Mol Endocrinol, 2000;14: 947-955.

Filiers H. Hypothalamus-Pituitary-Thyroid Axis. Encyclopedia of Neuroscience, 2009;1900-1903. doi: 10.1007/978-3-540-29678-2_2325

Finkelstein D., Andrianakis P., Luff AR., Wnalker D. Effects of thyroidectomy on development of skeletal muscle in fetal sheep. Am J Physiol, 1991;261, 1300-1306.

Forini F., Paolicchi A., Pizzorusso T., Ratto GM., Saviozzi M., Vanini V., Iervasi G. 3,5,3'-Triiodothyronine deprivation affects phenotype and intracellular $\left[\mathrm{Ca}^{2+}\right]_{\mathrm{i}}$ of human cardiomyocytes in culture. Cardiovascular Res, 2001;51(2):322-330.

Fox CS., Pencina MJ., D’Agostino RB., Murabito JM,. Seely EW., Pearce EN., Vasan RS. Relations of thyroid function to body weight: 
cross-sectional and longitudinal observations in a community-based sample. Arch Intern Med, 2008;168: 587-592.

Gereben B., Zavacki AM., Ribich S., Kim BW., Huang SA., Simonides WS., Zeold A., Bianco AC. Cellular and molecular basis of deiodinase-regulated thyroid hormone signaling. Endocr Rev, 2008;29: 898-938.

Gnocchi D., Steffensen KR., Bruscalupi G., Parini P. Emerging role of thyroid hormone metabolites 2016; 217(3):184-216. doi: 10.1111/apha.12648

Ichiki T. Thyroid hormone and atherosclerosis. Vascul Pharmacol, 2010;52:151-156.

Iwen KA., Schroder E., Brabant G. Thyroid hormone and the metabolic syndrome. Eur Thyroid J, 2013;2: 83-92.

Kim SR., Tull ES., Talbott EO., Vogt MT., Kuller LH. A hypothesis of synergism: the interrelationship of $\mathrm{T} 3$ and insulin to disturbances in metabolic homeostasis. Med. Hypotheses, 2002;59, 650666.

Knudsen N., Laurberg P., Rasmussen LB., Bulow I., Perrild H, Ovesen L., Jorgensen T. Small differences in thyroid function may be important for body mass index and the occurrence of obesity in the population. J Clin Endocrinol Metab, 2005;90: 4019-4024.

Lambadiari V., Mitrou P., Maratou E., Raptis AE., Tountas N., Raptis SA., Dimitriadis G. Thyroid hormones are positively associated with insulin resistance early in the development of type 2 diabetes. Endocrine, 2011;39(1):28-32.

Lin H., Mitasikova M., Dlugosova K., Okruhlicova L., Imanaga I., Ogawa K., Weismann P., Tribulova N. Thyroid hormones suppress $\varepsilon$ PKC signalling, down-regulate connexin-43 and increase lethal arrhythmia susceptibility in non-diabetic and diabetic rat hearts. J Physiol Pharmacol, 2008;59(2):271-85.

Liu YY., Brent GA. Thyroid hormone crosstalk with nuclear receptor signaling in metabolic regulation. Trends Endocrinol Metab, 2010;21: 166-173.

Luna-Vazquez F., Cruz-Lumbreras R., Rodríguez-Castelán J., Cervantes-Rodríguez M., Rodríguez-Antolín J., Arroyo-Helguera O., Castelán F., Martínez-Gómez M., Cuevas E. Association between the serum concentration of triiodothyronine with components of metabolic syndrome, cardiovascular risk, and diet in euthyroid post-menopausal women without and with metabolic syndrome. Springerplus, 2014,24(3):266.

Malhotra A., Penpargkul S., Scheuer J. The nature of contractile protein changes in hearts of diabetic rats. Circulation, 1979;60:11-1 2.

Mitrou P., Raptis S. A., and Dimitriadis G., Insulin action in hyperthyroidism: a focus on muscle and adipose tissue. Endocrine Reviews, 2010;31(5):663-679.

Moog N.K., Entringer S., Heim C., Wadhwa P.D., Kathmann $\mathrm{N}$., Buss, C. Influence of maternal thyroid hormones during gestation on fetal brain development. Neuroscience. 2015; S0306-4522(15)00897-0. doi: 10.1016/j.neuroscience.2015.09.070.

Motomura K., Brent GA. Mechanisms of thyroid hormone action. Implications for the clinical manifestation of thyrotoxicosis. Endocrinol Metab Clin N Am, 1998; 27: 1-23.

Mullur R., Liu YY., Brent GA. Thyroid hormone regulation of metabolism. Physiol Rev. 2014;94(2):355-82. doi: 10.1152/physrev.00030.2013.

Nishanth D., Sankar J., Vinay MV. Functions of Thyroid Hormones.Thyroid Disorders. Springer International Publishing, 2016; 11 25.

Ortega E., Koska J., Pannacciulli N., Bunt J.C., Krakoff J. Free triiodothyronine plasma concentrations are positively associated with insulin secretion in euthyroid individuals. Eur J Endocrinol, 2008;158, 217-221.

Ortiga-Carvalho T.M., Chiamolera M.I., Pazos-Moura C.C., Wondisford, F.E. Hypothalamus-Pituitary-Thyroid Axis. Comprehensive Physiology. 2016; 6:1387-1428. doi: 10.1002/cphy.c150027

Panchal SK., Wong WY., Kauter K., Ward LC., Brown L. Caffeine attenuates metabolic syndrome in diet-induced obese rats. Nutrition, 2012;28(10):1055-62. doi: 10.1016/j.nut.2012.02.013.
Park S., Scheffler TL., Gunawan AM., Shi H,. Zeng C., Hannon KM. Chronic elevated calcium blocks AMPK-induced GLUT-4 expression in skeletal muscle. Am J Physiol Cell Physiol, 2009;296(1):106-115

Quesada I., Todorova MG., Alonso-Magdalena P., Beltra M., Carneiro EM., Martin F., Nadal A., Soria B. Glucose Induces Opposite Intracellular $\mathrm{Ca}^{2+}$ Concentration Oscillatory Patterns in Identified $\alpha$ - and $\beta$-Cells Within Intact Human Islets of Langerhans. Diabetes, 2006;55: 2463-9.

Ribeiro MO., Carvalho SD., Schultz JJ., Chiellini G., Scanlan TS., Bianco AC., Brent GA. Thyroid hormone-sympathetic interaction and adaptive thermogenesis are thyroid hormone receptor isoformspecific. J Clin Invest, 2001;108: 97-105.

Roos A., Bakker S.J., Links T.P., Gans R.O., Wolffenbuttel B.H. Thyroid function is associated with components of the metabolic syndrome in euthyroid subjects. J. Clin. Endocrinol. Metab, 2007;92, 491496.

Saunders J., Hall SHE., Sonksen PH. Thyroid hormones in insulin requiring diabetes before and after treatment. Diabetologia, 1978,15:29-32.

Schlienger JL., Anceau A., Chabrier G., North ML., Stephan F. Effect of Diabetic Control on the Level of Circulating Thyroid Hormones. Diabetologia, 1982;22(6):486-8

Singh SP., Snyder AK. Effect of thyrotoxicosis on gluconeogenesis from alanine in the perfused rat liver. Endocrinology, 1978;102:182-187.

Spindel E., Arnold M., Cusack B., Wurtman RJ. Effects of caffeine on anterior pituitary and thyroid function in the rat. J Pharmacol Exp Ther, 1980;214(1):58-62.

Spindel E. R. and Wurtman R. J. (1984) Neuroendocrine effects of caffeine in rat and man. In Caffeine, Perspectives from Recent Research. Edited by P. B. Dews. pp. 119-128. Springer-Verlag, Berlin.

Spindel ER., Griffith L., Wurtman RJ. Neuroendocrine effects of caffeine. II. Effects on thyrotropin and corticosterone secretion. Journal of Pharmacology and Experimemtal Therapeutics, 1983;225, 346-350.

Stanick S., Vondra K., Pelikanova T., Vlcek P., Hill M., Zamrazil V. Insulin sensitivity and counter-regulatory hormones in hypothyroidism and during thyroid hormone replacement therapy. Clinical Chemistry and Laboratory Medicine, 2005;43(7):715-720.

Sundler F., Grunditz T., Hakanson R., Uddman R. Innervation of the thyroid. A study of the rat using retrograde tracing and immunocytochemistry. Acta Histochem Suppl, 1989;37:191-198.

Torrance CJ., Devente JE., Jones JP., Dohm GL. Effects of thyroid hormone on GLUT4 glucose transporter gene expression and NIDDM in rats. Endocrinology, 1997;138: 1204-1214.

Verga Falzacappa C., Mangialardo C., Madaro L., Ranieri D., Lupoi L., Stigliano A., Torrisi MR., Bouche M., Toscano V., Misiti S. Thyroid hormone T3 counteracts STZ induced diabetes in mouse. PloS One, 2011;6: e19839.

Wang C. The Relationship between Type 2 Diabetes Mellitus and Related Thyroid Diseases. Journal of Diabetes Research, 2013;(390534):9.. doi:10.1155/2013/390534

Wang YG., Dedkova EN., Fiening JP., Ojamaa K., Blatter LA., Lipsius SL. Acute exposure to thyroid hormone increases $\mathrm{Na}+$ current and intracellular $\mathrm{Ca}^{2+}$ in cat atrial myocytes. J Physiol, 2003;546(2):491-9.

Wennlund A., Felig P., Hagenfeldt L., Warhen J. Hepatic glucose production and splanchnic glucose exchange in hyperthyroidism. J Clin Endocrinol Metab, 1986;62, 174-180.

\section{How to cite this article:}

Silva LA, Wouk J, Weber VMR, Malfatti CRM, Osiecki R. Relation between diabetes mellitus, thyroid hormones and caffeine. J App Pharm Sci, 2017; 7 (03): 212-216. 